Izvorni znanstveni članak

Original scientific paper

\title{
UTJECAJ PORODNE MASE NA DNEVNI PRIRAST PRASADI VISOKOPLODNIH KRMAČA
}

\author{
D. Škorput, Z. Dujmović, Z. Luković
}

\begin{abstract}
Sažetak
Legla visokoplodnih krmača često karakterizira varijabilnost porodnih masa prasadi i češća pojava lagane prasadi manje vitalnosti, što može negativno utjecati na proizvodne pokazatelje prasadi u kasnijim fazama uzgoja. Stoga je cilj rada bio utvrditi utjecaj porodnih masa prasadi na farmi visokoplodnih $\mathrm{kr}$ mača na dnevne priraste prasadi u laktaciji i uzgoju. U istraživanje je bilo uključeno 296 prasadi iz prasenja 25 krmača hibridne linije Pen Ar Lan u razdoblju između prosinca 2014. i siječnja 2015. Analiziran je prosječni dnevni prirast prasadi od rođenja do kraja razdoblja uzgoja u dobi od 83 dana. Porodna masa značajno je utjecala na dnevne priraste prasadi tijekom laktacije i uzgoja. Prasad koja je pripadala razredima manjih porodnih masa imala je značajno manje dnevne priraste u odnosu na prasad koja je pripadala razredima s većim porodnim masama. Dobiveni rezultati upućuju na potrebu poduzimanja mjera s ciljem smanjenja broja avitalne prasadi manjih porodnih masa prasadi kako bi se omogućilo bolje preživljavanje i zadovoljavajući rast prasadi iz legala visokoplodnih krmača.
\end{abstract}

\section{Uvod}

U modernoj svinjogojskoj proizvodnji koriste se odabrani genotipovi životinja s ciljem postizanja visokih proizvodnih rezultata u svojstvima od ekonomskog značaja. Pretpostavka je da se selekcija na proizvodna svojstva, kao što su mesnatost, brzina rasta ili konverzija hrane približava optimumu, te daljnji selekcijski napredak nije lako postići bez negativnog utjecaja na ostala svojstva. Za razliku od proizvodnih svojstava, kod svojstava plodnosti zbog niske nasljednosti dugo nije bilo moguće postići značajniji genetski napredak. Međutim, uvođenjem preciznijih selekcijskih procedura, kao što je najbolje nepristrano linearno predviđanje (eng. Best linear unbiased prediction - BLUP), a u novije vrijeme i genomske selekcije, postignut je značajniji genetski napredak i u svojstvima plodnosti. Selekcija na veličinu legla, kao važno ekonomsko svojstvo u svinjogojskoj proizvodnji, posljednjih je godina rezultirala stvaranjem visokoplodnih linija krmača (Wolf i sur., 2008;000 piglets Luković i Škorput, 2015.). Visokoplodne linije krmača odlikuju se visokim brojem živooprasene prasadi. Međutim, povećanje broja živooprasene prasadi u leglu vrlo se često ne odražava na broju odbijene prasadi, zbog činjenice da broj prasadi u visokoplodnih linija krmača nadmašuje broj sisa te je zbog toga otežana othrana prasadi. Osim toga, kod većih legala pojavljuje se i problem velike varijabilnosti porodnih masa prasadi (Quinou i sur., 2002; Škorjanc i sur., 2007.), što nepovoljno utječe na pojavu većeg broja avitalne prasadi i slabiji postotak preživljavanja prasadi manjih porodnih masa. Niske porodne mase prasadi također negativno utječu na kasniji rast prasadi, rezultirajući smanjenim prirastima u kasnijim fazama proizvodnje (Quinou i sur., 2002.). Niske porodne mase nisu posljedica samo iznadprosječnih veličina legala, već mogu ovisiti o različitim faktorima, kao što su pasmina (Damgard i sur., 2003.) ili redni broj prasenja (Miligan i sur., 2002.).

Doc. dr.sc. Dubravko Škorput, Prof. dr. sc. Zoran Luković, Sveučilište u Zagrebu Agronomski fakultet, Svetošimunska cesta 25, Zagreb, Hrvatska;

Zrinko Dujmović, Veterinarska ambulanta Martes d.o.o., J. J. Strossmayera bb, Josipovac Punitovački, Hrvatska. 
S obzirom na navedeno, cilj rada bio je odrediti utjecaj porodne mase prasadi u leglima visokoplodnih krmača na dnevni prirast prasadi tijekom laktacije i uzgoja.

\section{Materijali i metode}

Istraživanje je obuhvatilo legla 25 krmača hibridne linije Naima - Pen Ar Lan koje su se prasile u razdoblju između prosinca 2014. i siječnja 2015. godine. Gravidne krmače premještene su u prasilište tjedan dana prije prasenja. Krmače su tretirane d-kloprostenolom 112. dana gravidnosti (Jančo i sur., 2016). Iznad svakog boksa za prasenje bila je postavljena grijaća lampa kako bi se osigurala dodatna toplina za prasad. Prasad je odbijena u prosječnoj dobi od 28 dana.Od petog dana prasenja do odbića, krmače su hranjene po volji. Unutar 18 sati nakon prasenja, prasad je individualno vagana, odstranjeni su sjekutići i repovi, te je prasad označena i razdvojena prema spolu. Trećeg dana nakon prasenja prasadi je aplicirana injekcija željeza. Veličina legla bila je standardizirana unutar dva dana nakon prasenja premještanjem prasadi manje porodne mase. Muška prasad kastrirana je trećeg dana života. Tijekom provođenja istraživanja prasad (Naima krmače x P76 Pen Ar Lan hibridni nerastovi) iz 25 legala vagana je pet puta: prvog dana nakon prasenja (PM), 14. dana života (T2), kod odbića 28. dana (T3), 30. dana u razdoblju uzgoja (T4), te na kraju razdoblja uzgoja u dobi od 83 dana (T5).

Opisna statistika izračunata je primjenom procedure MEANS programskog paketa SAS (SAS, 2009). Za analizu varijance i testiranje utjecaja u modelu za prirast do razdoblja od rođenja do 83. dana (DP) korištena je procedura GLM programskog paketa SAS. Za analizu utjecaja korišten je slijedeći statistički model:

$\mathrm{y}_{\mathrm{ijk} k}=\mu+\mathrm{L}_{\mathrm{i}+} \mathrm{P}_{\mathrm{j}+} \mathrm{S}_{\mathrm{k}+} \mathrm{e}_{\mathrm{ijk}}$

gdje je:

$\mathrm{y}_{\mathrm{ijkl}}$-dnevni prosječni dnevni prirast prasadi rođenja do 83. dana;

$\mathrm{L}_{\mathrm{i}}$-utjecaj veličine legla (ispodprosječna legla $<14$, prosječna legla 14 - 16 ; natprosječna legla $>16$ živooprasene prasadi);

$\mathrm{P}_{\mathrm{j}}$-redni broj prasenja;

$\mathrm{S}_{\mathrm{k}}$ - spol prasadi

$\mathrm{e}_{\mathrm{ijk}}-$ slučajna greška

Za potrebe istraživanja, tjelesna masa kategorizirana je u pet razreda: $\leq 1000 \mathrm{~g}, 1001-1200$ g, $1201-1400$ g, $1401-1600 \mathrm{~g} \mathrm{i} \geq 1600$ g. Veličina legla izražena je kao broj živooprasene prasadi (ŽOP) i kategorizirana u tri razreda: $<14$ ŽOP, $14-16$ ŽOP, $>16$ ŽOP.

\section{Rezultati i rasprava}

Opisna statistika za dnevni prirast prasadi, veličinu legla te porodne mase prikazana je u Tablici 1. U sva tri svojstva uočena je visoka varijabilnost, pri čemu je ona najizraženija kod porodne mase prasadi s koeficijentom varijabilnosti od $25,20 \%$. Visoka varijabilnost za navedena svojstva karakteristična je za populacije visokoplodnih krmača. 
Škorput i sur.: Utjecaj porodne mase na dnevni prirast prasadi visokoplodnih krmača

Tablica 1. Opisna statistika za veličinu legla, porodne mase i dnevni prirast prasadi

Table 1 Descriptive statistics for litter size, birth weights and average daily gain pf piglets

\begin{tabular}{lcccccc}
\hline \multicolumn{1}{c}{ Svojstvo } & Broj prasadi & Srednja vrijednost & SD & CV(\%) & Min & Max \\
\hline Ukupni dnevni prirast, g & 296 & 320,13 & 61,75 & 19,29 & 183,00 & 487,00 \\
\hline Broj živooprasene prasadi & 360 & 15,72 & 3,10 & 19,73 & 6,00 & 21,00 \\
\hline Porodna masa, kg & 360 & 1,33 & 0,34 & 25,20 & 0,40 & 2,22 \\
\hline
\end{tabular}

*SD - standardna devijacija; CV - koeficijent varijabilnosti

Od svih testiranih utjecaja u modelu, najizraženiji utjecaj na ukupni dnevni prirast prasadi na kraju razdoblja uzgoja imala je porodna masa. Također, uočen je statistički značajan utjecaj rednog broja prasenja, dok nije zabilježen značajan utjecaj veličine legla i spola na dnevni prirast prasadi tijekom laktacije i uzgoja (Tablica 2). Bérard i sur. (2008.) također nisu utvrdili značajan utjecaj veličine legla na priraste prasadi tijekom laktacije, za razliku od Bergstorma i sur. (2009.), koji su utvrdili su značajan utjecaj veličine legla na dnevni prirast prasadi tijekom laktacije. U istraživanju Škorjanca i sur. (2007.) također nije utvrđen značajan utjecaj spola na dnevne priraste prasadi u razdoblju uzgoja.

Tablica 2. Značajnost utjecaja na ukupni dnevni prirast prasadi Table 2 Significance of the effect on total daily gain in piglets

\begin{tabular}{lccccc}
\hline \multicolumn{1}{c}{ Izvor } & $\begin{array}{c}\text { Stupanj } \\
\text { slobode }\end{array}$ & $\begin{array}{c}\text { Suma } \\
\text { kvadrata }\end{array}$ & $\begin{array}{c}\text { Srednja suma } \\
\text { kvadrata }\end{array}$ & F vrijednost & P value \\
\hline Spol & 1 & 0,0000 & 0,0000 & 0,02 & 0,8841 \\
\hline Redni broj prasenja & 4 & 0,0350 & 0,0089 & 3,61 & 0,0068 \\
\hline Veličina legla & 2 & 0,0032 & 0,0016 & 0,67 & 0,5137 \\
\hline Porodna masa & 4 & 0,3123 & 0,0780 & 31,68 & $<0,0001$ \\
\hline
\end{tabular}

Tablica 3. Srednje vrijednosti dobivene metodom najmanjih kvadrata za dnevni prirast prema razredima porodnih masa

Table 3 Least square means for daily gain by birth weight classes

\begin{tabular}{|c|c|c|}
\hline Razred porodne mase & Srednja vrijednost & Standarda greška \\
\hline 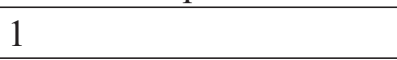 & $276,33^{\mathrm{A}}$ & 10,94 \\
\hline 2 & $298,49^{\mathrm{A}}$ & 9,62 \\
\hline 3 & $338,85^{\mathrm{B}}$ & 8,63 \\
\hline 4 & $354,83^{\mathrm{B}}$ & 8,58 \\
\hline 5 & $385,67^{\mathrm{C}}$ & 8,31 \\
\hline
\end{tabular}

$\mathrm{A}, \mathrm{B}, \mathrm{C}$ - vrijednosti označene različitim slovima različite su na razini $\mathrm{p}<0,05$

Najmanje dnevne priraste u uzgoju ostvarila je prasad koja je pripadala prvom razredu porodnih masa $(<1000 \mathrm{~g})$, dok je prasad koja je ostvarila najveće dnevne priraste u uzgoju pripadala razredu $\mathrm{s}$ najvećim porodnim masama $(>1600 \mathrm{~g})$. Razlika u prosječnom dnevnom prirastu dnevnom prirastu između razreda najteže i najlakše prasadi iznosila je 109,34 g. Nisu utvrđene značajne razlike između prvog i drugog, te trećeg i četvrtog razreda tjelesnih masa (Tablica 3). Razlike u dnevnim 
prirastima između prasadi različitih porodnih masa potvrđene su također istraživanjima Škorjanca i sur. (2007.). Također, značajan utjecaj porodnih masa na brzinu rasta prasadi u uzgoju utvrđen je istraživanjem Václavkove i sur. (2012.). Razlike u prirastima prasadi različitih porodnih masa tijekom laktacije mogu se objasniti činjenicom da teža prasad lakše može dosegnuti mliječnije sise te posisati veću količinu mlijeka u odnosu na lakšu prasad (King i sur., 2007.). Hurely i sur. (2001.) navode kako slobodan pristup prasadi sisama te vitalnija prasad većih porodnih masa, povećavaju proizvodnju mlijeka u mliječnoj žlijezdi, ne na taj način pozitivno utječu na brzinu rasta prasadi. Također, razlike u brzini rasta prasadi posljedica su i bioloških razlika između lakše i teže prasadi. Wigmore i Stickland (1983.) kao jedan od uzroka sporijeg rasta manje prasadi navode manji broj sekundarnih mišićnih vlakana. Porast protoka u krvi u maternici je nedovoljan da bi kompenzirao veći broj fetusa, što rezultira smanjenom opskrbom hranjivima potreban za intrauterini rast (Père i Etienne, 2000.). Smanjeni protok krvi negativno utječe na brojnost mišićnih vlakana. Smanjena brojnost mišićnih vlakana utjecat će na sporije priraste prasadi nakon prasenja. Alvarenga i sur. (2013.) kao uzrok sporijeg rasta manje prasadi navode zaostatak u razvoju probavnog sustava.

\section{Zaključci}

Porodna masa značajno je utjecala na dnevne priraste prasadi tijekom laktacije i uzgoja. Prasad koja je pripadala razredima manjih porodnih masa imala je značajno manje dnevne priraste $u$ odnosu na prasad koja je pripadala razredima s većim porodnim masama. Odlika velikih legala je povećana varijabilnost porodnih masa prasadi, s većim udjelom prasadi manjih porodnih masa, što predstavlja izazov u proizvodnji prasadi visokoplodnih krmača. Stoga se posebna pozornost treba usmjeriti na smanjenje broja avitalne prasadi kako bi se omogućilo bolje preživljavanje i zadovoljavajući rast prasadi iz legala visokoplodnih krmača.

\section{LITERATURA}

1. Alvarenga, A. L N., H. Chiarini-Garcia, P.C. Cardeal, L.P. Moreira, G.R. Foxcroft, D.O. Fontes, F.R.C.C. Almeida (2013.): Intra-uterine growth retardation affects birth weight and postnatal development in pigs, impairing muscle accretion, duodenal mucosa morphology and carcass traits. Reproduction, Fertility and Development, 25:387-395.

2. Bérard, J., M. Kreuzer, G. Bee (2008.): Effect of litter size and birth weight on growth, carcass and pork quality, and their relationship to postmortem proteolysis, Journal of. Animal Science 86:2357-2368.

3. Bergstrom, J. R., M.L. Potter, M. D. Tokach, S. C. Henry, S. S. Dritz, J. L. Nelssen, R. D. Goodband, J. M. DeRouchey (2009.): Effects of piglet birth weight and litter size on the preweaning growth performance of pigs on a commercial farm, Kansas State University Swine Day 2009. Report of Progress No. 1020. Kansas State Univ., Manhattan. 1-7.

4. Damgaard, L. H., L. Rydhmer, P. Løvendahl, K. Grandinson (2003.): Genetic parameters for within-litter variation in piglet birth weight and change in within-litter variation during suckling, Journal of Animal Science, 81(3), 604-610.

5. Hurley, W.L., A. Baldi, K. Stelwagen (2001.): Mammary gland growth in lactating sow. Special issue. In: Proceedings of the Fifth International Workshop on the Biology of Lactation in Farm Animals, Livestock Production Science, 70:1-2, 149-157.

6. Jančo, N., G. Jančo, D. Škorput, Z. Luković (2016.): Effect of d-cloprostenol application time on onset of partus in sows, in: Pospišil, M., Vnučec, I., Proceedings of 51st Croatian and 11th International Symposium on Agriculture, 347-350, Opatija, Croatia, 15-18 February 2016, Zagreb, Sveučilište u Zagrebu Agronomski fakultet. 
7. King, R.H., B.P. Mullan, F.R. Dunshea, H. Dove (1997.): The influence of piglet body weight on milk production of sows, Livestock Production Science 47 (1997), 169-174.

8. Luković, Z., D. Škorput (2015.): Factors influencing litter size in pigs. CAB Reviews: Perspectives in Agriculture, Veterinary Science, Nutrition and Natural Resources, 10.

9. Milligan, B.N., D. Fraser, D.L. Kramer (2001.): Birth weight variation in the domestic pig: Effects on offspring survival, weight gain and suckling behaviour, Applied Animal Behaviour Science, 73, 179-191.

10. Père, M. C., M. Etienne (2000.): Uterine blood flow in sows: Effects of pregnancy stage and litter size, Reproduction Nutrition Development. 40:369-382.

11. Quiniou, N., J. Dagorn, and D. Gaudré. (2002.): Variation of piglets' birth weight and consequences on subsequent performance, Livestock Production Science, 78:63-70.

12. SAS INST. INC., (2009.): The SAS System for Windows. Release 9.4 Cary, NC.

13. Škorjanc, D., M. Brus, M. Čandek-Potokar (2007.): Effect of birth weight and sex on pre-weaning growth rate of piglets. Archives of Animal Breeding, 50, 476-486.

14. Václavková E., P. Daněk, M. Rozkot (2012.): The influence of piglet birth weight on growth performance, Research in pig breeding, 6 (2):59-61.

15. Wigmore, P. M. C., N.C. Stickland (1983.): Muscle development in large and small foetuses, Journal of Anatomy, 137:235-245.

16. Wolf, J., E. Žakova, E. Groeneveld (2008.): Within-litter variation of birth weight in hyperprolific Czech Large White sows and its relation to litter size traits, stillborn piglets and losses until weaning, Livestock Science, 115, 195-205.

\section{EFFECT OF BIRTH WEIGHT ON DAILY GAIN IN PIGLETS FROM HIGH PROLIFIC SOWS}

\section{Summary}

Litters from high prolific sows are characterised by the variability of birth weights of piglets and higher frequency of light and avital piglets, which can negatively affect production results of piglets in following production stages. The aim of the paper was to determine effect of birth weights of piglets from farm with high prolific sows on average daily gains of piglets in lactation and nursery phase. The study included 296 piglets from 25 sows of Pen Ar Lan hybrid lines farrowed between December 2014. and January 2015. The focal variable was average daily gain of piglets from birth to the end of nursery phase. Birth weight had significant effect on daily gains of piglets during lactation and nursery phase. Piglets from the classes with lower birth weights had significantly lower average daily gains in analysed period compared to piglets with higher birth weights. Results obtained in this study show the necessity of reducing the number of avital piglets with low birth weights in order to enable higher survival rate and optimal growth rate of piglets from litters of high prolific sows.

Primljeno: 23.05.2018.

Prihvaćeno: 01.12.2018. 